\title{
Repensar a comunicação com Raymond Williams: estrutura de sentimento, tecnocultura e paisagens afetivas ${ }^{1}$
}

\author{
Itania Maria Mota Gomes' \\ https://orcid.org/0000-0001-8876-7318 \\ Elton Antunes" \\ https://orcid.org/0000-0002-5265-6584 \\ I - UFBA \\ Salvador (BA), Brasil \\ II - UFMG \\ Belo Horizonte (MG), Brasil
}

Resumo: Neste texto, indicamos a importância da hipótese cultural de estrutura de sentimento, de Raymond Williams, para as discussões e análises que tomam a noção de historicidade como decisiva para as reflexões em torno das práticas comunicativas e culturais. Partimos do reconhecimento de que tal noção permite levar em consideração distintas temporalidades que marcam todo processo social e oferece elementos para pensar metodologicamente o trabalho com textos/textualidades e formas da comunicação, em articulação com a dimensão política que deve marcar essa iniciativa. Elegemos, em nosso percurso, três entradas temáticas para refletirmos a partir, com e para além de Williams: 1) o gesto epistemológico em torno da noção de estrutura de sentimento; 2) a apreensão das determinações e determinismos tecnológicos; 3) sua contribuição para compreendermos os engajamentos identitários, em articulação com paisagens afetivas, aspectos decisivos para se pensar o contemporâneo.

Palavras-chave: estrutura de sentimento; paisagens afetivas; tecnocultura, materialismo cultural.

Abstract: Rethinking communication with Raymond Williams: structure of feelings, technoculture and affective landscapes - This paper points out the importance of Raymond Williams' cultural hypothesis of structure of feeling for the discussions and analyses that take the notion

1 Este artigo é a versão final de duas comunicações orais (GOMES \& ANTUNES, 2018; ANTUNES \& GOMES, 2018) apresentadas pelos autores nos dois encontros da Rede Historicidades dos Processos Comunicacionais, do ano de 2018. A pesquisa que resultou neste artigo foi financiada com bolsas de Produtividade em Pesquisa do Conselho Nacional de Desenvolvimento Científico e Tecnológico/CNPQ, recebida por ambos autores. 
of historicity as decisive for the reflections on communicative and cultural practices. We start from the recognition that this notion allows to take into account different temporalities that mark every social process and offers elements to think methodologically the work with texts / textualities and forms of communication in articulation with the political dimension that should mark such an initiative. We chose in our course three thematic inputs to reflect from, with and in addition to Williams: 1) the epistemological gesture around the notion of structure of feeling; 2) the seizure of determinations and technological determinisms; 3 ) its contribution to understand contemporary identity engagements in articulation with affective landscapes, decisive aspects to think contemporaneity.

Key-words: structure of feeling; affective landscapes; technoculture, cultural materialism.

\section{Assentando premissas}

Neste ensaio, argumentamos que o trabalho de Raymond Williams é fundamental para as discussões e análises que tomam a noção de historicidade como decisiva ao aprimoramento das reflexões em torno das práticas comunicativas e culturais. Partimos do reconhecimento de que a hipótese cultural de estrutura de sentimento é uma entrada formidável para tal discussão, na medida em que permite levar em consideração distintas temporalidades que marcam todo processo social (organizadas em torno das dimensões do arcaico, residual, dominante, novo e emergente), oferecendo elementos para pensar metodologicamente o trabalho com textos/textualidades e formas da comunicação, em articulação com a dimensão política que deve marcar essa iniciativa.

Não se trata, todavia, de investigar as análises de Williams sobre um conjunto de fenômenos contemporâneos no âmbito da comunicação e da cultura, mas de percorrer alguns de seus apontamentos teóricos como forma de oferecer pistas para abordar questões específicas a certas conjunturas, conforme propugnava o próprio autor.

Elegemos, em nosso percurso, três entradas temáticas para refletirmos a partir, com e para além de Williams: 1) o gesto epistemológico em torno da noção de estrutura de sentimento, para o pensar da comunicação e suas formas de conhecer; 2) a apreensão das determinações e determinismos tecnológicos, especialmente em sua ênfase na materialidade; 3) sua contribuição para a compreensão do contexto na relação com os contemporâneos engajamentos identitários, em articulação com paisagens afetivas. Essas temáticas sinalizam campos conceituais interdependentes, separados aqui apenas para efeitos de clareza dos argumentos.

É importante, para a reflexão pretendida, indicar o horizonte teórico e os aspectos políticos que estruturam o pensamento de Williams. A primeira premissa é de que se trata de uma teoria engajada com a promoção da transformação social. O autor faz um esforço teórico-metodológico em rejeitar o determinismo marxista e empreender uma análise cultural que seja, ao mesmo tempo, a análise da relação entre os elementos de um modo inteiro de vida e um empenho político de enfrentar o capitalismo (WILLIAMS, 1979, p. 76). 
Por isso, torna-se fundamental, para ele, valorizar a mudança cultural, a inovação, a concepção de que é possível o surgimento, nos termos da tradição marxista, de uma nova classe social, de uma nova consciência de classe e, ao menos em tese, de uma nova hegemonia. A articulação entre a mudança social e a mudança cultural é o desafio central que Williams quer enfrentar com a noção de estrutura de sentimento.

Diferentes analistas reconhecem que o trabalho de Williams se situa na interseção entre três campos: a sociologia cultural, a comunicação e os estudos culturais (JONES, 2016), operando a partir da articulação com a ideia de materialismo cultural, que permite pôr em relação o que acontece em uma dada sociedade e as formas culturais que essa sociedade acolhe. Williams visa, com isso, ultrapassar a perspectiva marxista de abordagem em torno da aporia entre "superestrutura ideológica" e "infraestrutura material". Para ele, não se trata de apontar um plano da cultura como esfera própria e particular de ação social, como atividade de representação de um grupo social ou como determinação e projeção de outra esfera da realidade (política, econômica etc.). Mas é preciso reconhecer que algum dualismo permanece em sua obra, mesmo que permanentemente reelaborado até a formulação alcançada em Marxismo e Literatura (FUCHS, 2017; JONES, 2016) e em trabalhos posteriores, especialmente com sua apropriação à noção de hegemonia de Antonio Gramsci.

A partir de Williams, pode-se perceber o desenvolvimento de uma perspectiva de compreensão das culturas em torno de dimensões arcaicas, residuais, dominantes, novas, emergentes e cotidianas, vistas em seu processo de configuração e necessariamente de mudança, ancorada em noções teóricas e conceitos radicalmente contextuais, perspectiva que se consolidou na abordagem dos estudos culturais (GROSSBERG, 2010; 2015). Não consiste em desenvolver uma teoria geral ou um método particular, mas em pensar contextos como múltiplas, complexas e contraditórias relações, e conhecê-los sem reduzir tal complexidade.

A segunda premissa que nos interessa, e sobre a qual parece haver mesmo certo consenso entre os pesquisadores, é de que a crítica de Williams ao determinismo tecnológico, sua proposição da noção de "estrutura de sentimentos", a análise da cultura e o materialismo cultural como modo de análise contribuem para uma teoria da comunicação para a mudança social (THOMAS, 2017).

Williams abordou a cultura como um sistema social, material e produtivo - uma espécie de cultura-como-produção. Assim, os meios de comunicação foram repensados como meios de produção comunicativa e cultural, o que não equivale de modo algum às perspectivas da economia política das indústrias culturais (JONES, 2016). A produção comunicativa implica relações sociotécnicas de produção cultural, enquanto seus produtos incluem formas culturais estéticas.

Essas duas proposições permitem a Williams formular uma espécie de programa de investigação sobre a comunicação, cujas questões mais promissoras estão em torno: 
1) dos vínculos entre comunicação e cultura (algo como o pressuposto de que processos comunicativos se dão em e por meio de processos culturais); 2) da tradição cultura-esociedade (cultura não pode ser compreendida sem referência à sociedade, às práticas sociais dos grupos e indivíduos); 3) da ideia de que, compreender a comunicação, é necessário partir não da noção de meio, mas da noção de prática; 4) da noção de uma sociologia da cultura que, como ele dizia, deveria superar a distinção entre uma sociologia dos meios e uma sociologia dos públicos e adotar como princípio fundamental a unidade complexa dos elementos; 5) do fato que os receptores pertencem, em um contexto de análise politicamente interessado, às classes trabalhadoras (o que evitaria pensar os receptores como massa). O trabalho com textos/textualidades/formas da comunicação é feito de modo a incluir a perspectiva dos públicos, sem necessariamente fazer pesquisa empírica de recepção - um modo de lidar com preferências, engajamentos, enfim, com as experiências incrustradas nos textos, que são pensados como práticas, constituídas como lugar para considerarmos a tal da unidade complexa dos elementos.

Esse programa nos sugere algumas tarefas para a atualização do pensamento do autor na direção do contemporâneo e das questões que alcançam a comunicação e a cultura. São questões, como dissemos, relativas à materialidade da tecnologia, à reconfiguração da política, à ação dos movimentos sociais e ao próprio movimento de compreensão do que ocorre no mundo hoje.

\section{Estrutura de sentimentos - ou gestos epistemológicos para lidar com a comunicação}

A noção de estrutura de sentimento pode nos permitir lidar com a historicidade relações temporais, épocas e tempos específicos, inclusive os atuais - sem as condicionantes ou problemáticas da reflexão própria ao campo da historiografia. Ao acionarmos essa noção, torna-se decisivo operar com alguns movimentos de forma concomitante. O primeiro diz respeito a considerar elementos especificamente afetivos da conformação das relações sociais. Em segundo lugar, é preciso não lidar com tais dimensões apenas como constituintes de representações, elementos cuja substância equivaleria à visão de mundo ou ideologia. Da mesma maneira, devemos tomar os processos coletivos/compartilhados, nos quais compreensão, cognição, gestos, interpretações e linguagem estejam interligados e existam não percebidos de forma consciente pelos agentes, mas incorporados em práticas culturais. Nessa perspectiva, o sentimento não tem uma natureza pessoal, mas diz daquilo que está manifestado em objetos e práticas. Por fim, devemos perceber que a estrutura de sentimento traz uma perspectiva aporética: precisamos distinguir e estudar aspectos específicos da vida cultural e das práticas, mas queremos, ao mesmo tempo, visá-las pensando em como elas foram experimentadas, como partes inseparáveis de uma complexa experiência social em solução (WILLIAMS, 1979), que ainda não se precipitou/ cristalizou em determinadas formas e práticas. 
A estrutura de sentimento opera como ferramenta analítica potente quando lidamos com sociedades/processos em momentos de transição: mudanças formais nas práticas culturais; alteração nas convenções e nos meios de expressão. É decisivo lidar com o dominante (nos termos de Gramsci), mas articulado com a cultura emergente, pela qual ele entende novos significados e valores, novas práticas, novos relacionamentos e tipos de relacionamentos (WILLIAMS, 1979, p.134). Como ressalta Gomes (2011), é importante levar em consideração a distinção que Williams fará entre os elementos de alguma fase nova da cultura dominante e os que lhe são substancialmente alternativos ou opostos na cultura dominante: "emergente no sentido rigoroso, e não simplesmente novo" (WILLIAMS, 1979, p. 126).

Em Cultura, livro mais tardio, de 1981, a definição do emergente surge de modo mais preciso para as discussões que nos interessam na relação com as historicidades:

[...]o emergente é correlato, mas não é idêntico ao inovador. Alguns tipos de inovação [...] são movimentos e ajustamentos dentro do dominante e tornamse suas novas formas [...]. Não há análise mais difícil do que aquela que, em face de novas formas, deve procurar determinar se essas são novas formas do dominante ou se são genuinamente emergentes. Na análise histórica, a questão já está assentada: o emergente torna-se o emergido [...] e depois, muitas vezes, o dominante. Mas na análise contemporânea, exatamente devido às relações complexas entre inovação e reprodução, o problema se encontra em nível diferente (WILLIAMS, 1992, p. 202-203).

Na perspectiva de Williams, práticas culturais devem ser estudadas a partir da experiência vivida e das práticas cotidianas de atores historicamente situados. Esse estudo deve prestar atenção tanto às dimensões cognitiva, afetiva e estética dos modos textuais e expressivos, quanto às suas características formais. Nesse viés, a noção de estrutura de sentimento sugere que talvez possamos (e precisemos) renovar alguns aspectos para compreender os fenômenos da comunicação como cultura. Como indiciar, contemporaneamente, a partir da comunicação e da cultura, processos de mudanças efetivos em quadros societais em que a ideia de transformação apareça como leimotiv na apreciação da vida social?

Tomemos a noção de meios de comunicação, central em diferentes modos de pensar a comunicação e estruturante da forma como Williams desenvolve seu pensamento. Uma das características mais marcantes dos estudos é a compreensão e a afirmação dos vínculos entre comunicação e cultura e sua compreensão de que a cultura contemporânea se caracteriza pela presença dos meios e das tecnologias da comunicação. Se as ideias de mídia ou de meios de comunicação sempre trouxeram implicações metodológicas para a pesquisa em comunicação - formas de estudar, referências empíricas etc. -, esse lugar de análise se apresenta revolvido não apenas pelo desenvolvimento até aqui alcançado, em termos de compreensão de tais fenômenos, mas também por uma dinâmica dos processos 
culturais em que sobreposições, superposições e transfigurações das práticas comunicativas tornam impossível lidar com os até então modos característicos de estudo. As textualidades midiáticas e as formas da comunicação são, em certo sentido, abordagens que sinalizam a ultrapassagem das perspectivas midiacêntricas da comunicação e da cultura. É, de certa maneira, o que o autor faz ao tratar da noção de convenção, "aqueles meios de expressão que têm consenso tácito" como uma parte vital da estrutura de sentimento: "enquanto a estrutura muda, novos meios [de expressão] são percebidos e compreendidos, enquanto velhos meios começam a parecer vazios e artificiais" (WILLIAMS, 2001, pg. 33), numa articulação estreita entre a mudança social e a mudança cultural. Para Raymond Williams (2001, pg. 36), mudanças nas convenções artísticas nunca são casuais ou fruto de meras escolhas técnicas, mas estão essencialmente relacionadas a mudanças na estrutura de sentimento de determinada sociedade.

Curiosamente, na contemporaneidade, o quadro de estudo da comunicação tende a priorizar ou a se restringir ao estudo dos meios, partindo de leitura ligeira da importância crescente e do papel de determinação exercido pela mídia. Acaba-se por, ao estudar a comunicação, muitas vezes, investigar o funcionamento do que se entende por mídia. Ora, não está em causa apenas o fato de que tal priorização da mídia, enquanto aparato sociotécnico, leva-nos a minimizar a intervenção dos interlocutores, abandonando o processo comunicativo; tampouco que esse procedimento reduz a apreensão da dinâmica de produção de sentidos que acontece paralelamente à intervenção dos meios de comunicação, marcada por eles ou à sua revelia. Mas, se o lugar da mídia não pode ser ignorado e nem ela pode ser tomada pela integralidade do processo de comunicação, a questão que nos aparece é que, mesmo numa perspectiva não reducionista da comunicação ao midiático, permanece de fundo a ideia muito pouco problematizadora dos meios enquanto tal. Dados estáveis, disponíveis para uma apreensão imediata, apresentam-se não como lugar de mudança, mas como operadores autônomos e distantes de percepção crítica da análise enquanto meios de transformação e em transformação.

Qual seria, então, o escopo adequado para se tratar da questão da mídia? Se os meios de comunicação não são fenômenos à parte da realidade social, que dimensão ocupam quando se trata da análise das práticas sociais enquanto práticas comunicativas? Se pensarmos a partir da noção de estrutura de sentimento, dirão respeito a formas vivas, de linhas entrelaçadas de percepção, materialidades, discursos, textualidades, técnicas, experiências articuladas como uma malha, e não como algo que delimita, circunscreve, define um próprio/particular e, assim, favorece a cristalização entre interior e exterior de meios ditos específicos.

Estrutura de sentimento nos remete ao universo dos meios como tecnologia e forma cultural, como fenômenos que têm natureza flexível e dispersa, circunstancialmente capturáveis em uma forma empírica, que envolve o desvelamento de dinâmicas sincrônicas e diacrônicas de configurações comunicacionais. A constituição das mídias não é 
de base exclusivamente tecnológica, mas sociotécnica - são parte dos modos como se dão as relações entre tecnologia e cultura, uma tecnocultura.

\section{Tecnoculturas}

Há certa tendência, talvez ainda hegemônica nos estudos de comunicação, em enfatizar o processo de transformação tecnológica e avaliá-lo como uma sucessão de inovações. Por vezes, esquecemos que, em épocas passadas, ocorreram também certas dinâmicas em torno das tecnologias, indicando já uma inadequação de trabalhar com a ideia de fronteiras nitidamente demarcadas entre os meios. Dessa maneira, sair das cronologias simples, das causalidades ou monocausalidades na interpretação das mídias, abandonar a percepção de inevitabilidades ou de convergências, da tecnologia ora neutra ora determinista, é uma perspectiva que pode ser encontrada na base das reflexões de Williams. Trata-se de enfatizar a heterogeneidade de base que constitui as tecnologias e, mais do que suportes, meios, tecnologias, lidar com aspectos que envolvem uma cultura que alimenta e é alimentada por um complexo de práticas midiáticas e organiza instituições cruciais da sociedade contemporânea - ou seja, lidar com tecnoculturas.

A abordagem que o autor faz da televisão (WILLIAMS, 2016) é exemplar. A televisão, como instituição, tecnologia e forma cultural, tem passado por um processo de intensa transformação devido a inovações tecnológicas, mas também por conta de alterações nas práticas industriais de produção, criação e circulação, com a revisão dos marcos regulatórios e da legislação trabalhista, com as reconfigurações de hábitos e expectativas das audiências e com as disputas por reconhecimento.

Nesse sentido, Williams ajudou a formatar a perspectiva de uma crítica cultural que busca recuperar a complexa rede de relações sociais, políticas, econômicas, que é prérequisito para a produção do trabalho. Os estudos culturais reconhecem que as relações entre cultura e tecnologia são relações de poder, em especial quando se trata de tecnologias da comunicação. Mas a ênfase nos processos de produção de sentido na cultura permite rejeitar a abordagem tecnologicamente determinista, com seu duplo desdobramento seja certo pensamento tecnofóbico, seja o mito da revolução tecnológica - e observar as apropriações cotidianas das tecnologias. Entretanto, se o destaque dado ao modo como produzimos sentido em nossas práticas da vida cotidiana leva a considerar a diversidade de apropriações, o procedimento de examinar tais práticas do ponto de vista da sua articulação com as relações de poder serve de antídoto contra qualquer populismo, político ou cultural.

Então, parece-nos que uma abordagem possível, sinalizada a partir de Williams, é pensar a comunicação contemporaneamente a partir da específica articulação entre tecnologia e cultura, uma tecnocultura (cf. GOMES, 2015). Em termos conceituais e empíricos, tecnocultura diz respeito ao modo como vivemos, individualmente, 
mas sempre de modo compartilhado, as tecnologias. Pensada efetivamente como articulação entre tecnologia e cultura, ela não se refere, pura e simplesmente, à tecnologia e nem à cultura, mas às apropriações e interpretações da tecnologia na vida cotidiana, para lidar com problemas, questões e necessidades colocadas pela vida, em sintonia com afetos, desejos, valores e práticas sociais. Tecnocultura se refere a uma relação que convoca nosso olhar para dinâmicas políticas, sociais, econômicas e simbólicas da vida cotidiana.

A questão passa a ser como, no nosso universo conceitual, deslocarmos novamente a noção de mídia. Talvez, ao reconhecer que, em cada quadro histórico e contexto societal específico, desenhamos linhas imaginárias e arbitrárias entre objetos diversos, coisas, objetos técnicos, plataformas, agentes, formas simbólicas que conformam materialidades peculiares, mas não inaugurais, a partir de paisagens afetivas conformadas em articulações peculiares de estruturas de sentimento, possamos superar abordagens midiacêntricas, colocando em perspectiva cenários analíticos mais complexos, para a articulação entre comunicação e cultura. É preciso submetermos as materialidades comunicativas ao crivo da história, das circunstâncias, das misturas, das incorporações e das transformações, para vermos, inclusive, os modos como essa tecnocultura se apresenta como campo de disputa, de conflito, de luta, e não apenas terreno onde a transformação se dá.

\section{Paisagens afetivas e lutas identitárias}

Estrutura de sentimento está na origem da abordagem que Lawrence Grossberg dá ao conceito de afeto. Em entrevista publicada no livro The Affect Theory Reader, Grossberg argumenta que a questão do afeto lhe apareceu, pela primeira vez, por meio do conceito de estrutura de sentimento, de Raymond Williams, e do modo como Richard Hoggart tentou "definir a questão dos estudos culturais em termos de algo como 'o que é estar vivo' em um certo tempo e lugar" (GROSSBERG, 2010b, p. 310). Sua percepção dos estudos culturais, especialmente suas investigações sobre o fenômeno do rock, levavam a crer que as questões de ideologia e experiência não permitiam a abordagem do que Williams estava buscando compreender com estrutura de sentimento, ou seja, o modo como vivemos as relações entre elementos econômicos, sociais, materiais e culturais, que formam um modo integral de vida e que dizem respeito à vida cotidiana. "Vida cotidiana não é simplesmente as relações materiais; é uma estrutura de sentimento, e é aí que quero localizar o afeto" (GROSSBERG, 2010b, p. 313). Grossberg chama a atenção para o fato de que estrutura de sentimento se conecta cada vez mais explicitamente, no trabalho de Williams, com a questão dos elementos emergentes (GROSSBERG, 2010b, p. 317) e com o acesso à relação entre o vivível e o articulável. Para Grossberg, estrutura do sentimento tem a ver com os limites da significação, da representação, referindo-se àqueles elementos presentes na produção discursiva, mas que não são capturados por noções de significação ou representação. É naquela espécie de lacuna entre o que pode 
ser traduzido como significativo ou cognoscível e o que é vivível que ele localiza o afeto (GROSSBERG, 2010b, p. 318).

Afeto tem sido compreendido por Grossberg como algo que organiza, disciplina, mobiliza e coloca nossa atenção, volição, humor e paixão a serviço de agendas específicas (cf. GROSSBERG, 1992, p. 255), configurando mapas de importância a partir dos quais agimos em nossas vidas cotidianas. Como elemento que faz parte da luta por hegemonia, o afeto é também algo que tenta transformar os mapas de importância dos sujeitos e a natureza e os locais de autoridade da vida contemporânea (GROSSBERG, 1992, p. 255), organizando, a partir de uma perspectiva temporal, os sentidos em relação a valores e disposições que circulam na cultura.

As historicidades dos afetos nos interessam (suas transformações no tempo), mas acreditamos que Williams e Grossberg nos autorizariam a propor outra articulação, a do afeto como figura de historicidade. Na conexão entre Williams e Gramsci, Grossberg encontra, por exemplo, um caminho de estudo do rock pela perspectiva "do poder como a organização do desejo", e passa a considerar que os afetos em torno do rock se organizam a partir da vida material cotidiana de seus públicos, inscritos na realidade social "marcada apenas por sua alteridade, sua existência fora das possibilidades afetivas da cultura dominante" (GROSSBERG, 1997, p.31).

Aparatos afetivos constroem sentimentos de existência, constituem o registro pelo qual valoramos, construímos individualidade, ligamo-nos ao real, ancoramo-nos às nossas vidas, pertencemos a certos lugares e trajetórias, organizamos nossa relação com o outro. Afeto

é uma dimensão ou ingrediente essencial das desordens da experiência humana, e é pelo menos tão complicada quanto as outras dimensões - de corpos biológicos, relações e estruturas sociais, e significado e consciência. [...] Como o plano do significado, o afeto é o produto contingente de eventos, contradições e lutas humanas e não humanas. Varia ao longo do tempo e do local e é distribuído de forma desigual pelas populações. Se o significado é como fazemos sentido do que está acontecendo, afeto é a energia que permeia todas as nossas experiências e define como é viver em um momento. Como o significado, o afeto é sempre constituído no espaço entre individualidade e socialidade, entre consciência e materialidade, entre o cognoscível e o ainda não-articulado. O afeto engloba uma variedade de maneiras pelas quais 'sentimos' o mundo em nossa experiência, incluindo humores, emoções, mapas do que importa e sobre com que nos preocupamos, prazeres e desejos, paixões, sentimentos etc. (GROSSBERG, 2018, p.10-11).

Esse é um aspecto que particularmente destacamos no trabalho de Lawrence Grossberg sobre os investimentos afetivos no rock: a hipótese de que o contexto afetivo do rock and roll é mais temporal que sociológico (GROSSBERG, 1997, p. 31) e de que 
o rock é uma formação cultural emergente (GROSSBERG, 1997, p. 35), no sentido de Raymond Williams. O rock surge num contexto temporal particular, caracterizado pelo capitalismo tardio ou pós-modernidade, que produziu uma geração de crianças que não estavam apenas entediadas e com medo, mas solitárias e isoladas umas das outras e do mundo adulto também. Ao mesmo tempo, esse mundo estava em constante mudança. Mas o que é único e apenas aparentemente contraditório é que a mudança é tudo o que há, sem nenhum sentido estável ou teleológico, sem passado e sem futuro: a história parecia ter entrado em colapso. O rock emerge e ganha sentido, nesse contexto, como uma prática "através da qual alianças afetivas são produzidas, através da qual outras práticas e acontecimentos são investidas de afeto" (GROSSBERG, 1997, p. 35).

Nesse sentido, o rock é um modo de lidar com o tempo, um modo de lidar com uma formação histórica emergente: ele transforma "um momento histórico particular e a geração que emergiu com ele - em uma ruptura aparentemente permanente. Essa ruptura é realizada através da produção de 'alianças afetivas'" (GROSSBERG, 1997, p. 37). O rock seria, então, definido mais pelos investimentos afetivos que se constituem como práticas de empoderamento estratégico do que por representações semióticas ou práticas de significação e produção de sentido. Grossberg convoca mesmo a expressão "formações afetivas" para afirmar sua relação com formações ideológicas, políticas e econômicas, mas, no mesmo movimento, mostrar a irredutibilidade do afeto às questões ideológicas, políticas e econômicas.

Da mesma forma, ao tratar do cenário estadunidense das eleições de Donald Trump, Grossberg retoma sua crítica à ênfase dos estudos culturais sobre as ideologias e as representações ideológicas. A eleição de Trump não se explicaria nem pela formação de um consenso ideológico nem por um consentimento hegemônico, já que o grupo dominante, nesse caso, seria formado por forças contraditórias demais, fraturadas demais para constituirem-se como bloco hegemônico, e não se vê esforços para forjar compromissos em torno de determinadas pautas. Sua hipótese é de que a vitória de Trump foi construída de forma afetiva, articulando e organizando o campo das emoções, paixões, humores (cf. GROSSBERG, 2018, p. 43-44), e propõe a ideia de paisagens afetivas como uma configuração de estruturas de sentimento (Ibidem, p. 93).

Grossberg retoma Raymond Williams e propõe pensar estruturas de sentimento como pontos de articulação entre o que já é conhecido e experimentado e o surgimento de novas experiências que ainda não podem ser expressas e, portanto, permanecem desconhecidas. Ele investiga os modos como elas definem ecologias de pertencimento e possibilidades de mudança.

Uma paisagem afetiva descreve um modo social complexo de estar no mundo, um espaço densamente texturizado no qual algumas experiências, comportamentos, escolhas e emoções são possíveis, alguns "sentimos" inevitáveis e óbvios, e outros 
ainda são impossíveis ou inimagináveis. Define o que é permitido e o que é proibido. E é aí que a luta para tornar experiências novas e emergentes, vivíveis e conhecíveis, é levada a cabo (GROSSBERG, 2018, p. 91).

Se paisagens afetivas dizem das ecologias de pertencimento e constituem-se como práticas de empoderamento estratégico, que implicações as relações entre estrutura de sentimento e afeto têm para a compreensão das identidades e para as lutas identitárias? $\mathrm{E}$, se estrutura do sentimento tem a ver com os limites da representação e se refere àqueles elementos que não são capturados por noções de significação ou representação, como podemos acessá-los? Quais são os sentidos para políticas de identidade, hoje, da "diferença entre lutar por uma identidade (um problema cultural) e lutar contra várias práticas políticas que subordinam/oprimem grupos específicos precisamente pela construção das identidades que estão envolvidas" (GROSSBERG, 2018, p. 21-22)?

Na maior parte das perspectivas, dentro dos estudos culturais, a identidade é um conceito sob rasura, sobre o qual não podemos mais falar como antes, em termos de essência, homogeneidade e pureza, mas um conceito sem o qual não podemos pensar questões colocadas pela modernidade e pela globalização. Nenhuma identidade é pura e única; nenhuma identidade é fixa. As identidades são híbridas, heterogêneas, fragmentadas. Os estudos feministas e os estudos sobre raça são duas "interrupções" na história da formação dos estudos culturais, que sinalizam a importância do pessoal como político e a centralidade das questões de gênero, sexualidade e raça para a compreensão das relações entre cultura, poder e representação (HALL, 2003). Os anos 90 se configuraram, nos estudos culturais, como o auge das discussões sobre as políticas identitárias, com ênfase no pessoal como político, nas textualidades e no discurso. As investigações e problematizações construídas pelas perspectivas dos movimentos negros e feministas colocaram novos problemas, tomaram outros desafios e chamaram a atenção para os vínculos simbólicos que constituem as identidades.

\section{Considerações finais}

Compreender a mudança implica uma forte ênfase na análise histórica. Destacamos um aspecto importante da compreensão da análise da cultura nos termos de Raymond Williams: sua crucial vinculação com a história não visa a compreender o passado, no sentido estrito, mas a descobrir as tendências, identificar os movimentos que regem a mudança. Williams afirma que o analista precisa considerar as diversas temporalidades sociais em qualquer análise da cultura e estar atento a certo senso de movimento, de processo histórico, de conexões com o futuro e o passado, de articulações complexas entre esses elementos dominantes e os residuais e emergentes. Nesse sentido, o autor afirma que é "com as formações emergentes que a estrutura de sentimento, como solução, se 
relaciona" (WILLIAMS, 1979, p. 136), pois estrutura de sentimento tenta captar valores e sentidos no momento de sua emergência.

A perspectiva do materialismo cultural de Williams está, assim, assentada no que Grossberg chama de prática de contextualização radical. Os olhares analíticos e o interesse de investigação se voltam para a vida ordinária, cotidiana, para a cultura popular, lembrando sempre que aí estão sujeitos em luta política. Isso pode nos ajudar a entender, no campo da comunicação, os processos de engajamento e lutas identitárias da contemporaneidade, em que os modos particulares, as condições específicas da experiência são lugares de conhecimento e de luta política. Se o contexto pode ser compreendido como as relações que foram construídas como relações de força, no interesse de certas posições de poder, a luta para mudar o contexto envolve a luta para mapear essas relações e, quando possível, desarticulá-las e rearticulá-las, construindo outras conexões possíveis.

A articulação demanda movimentos de desconstrução e de reconstrução, pois é preciso desconstruir o modo como contextos são apresentados como um todo harmonioso, sem rachaduras, e evidenciar suas contradições, as peças diversas e divergentes que o constituem. Desestabilizar essas peças seria a própria definição de uma análise contextual radical nos estudos culturais. Assim, certos tipos de luta política e de construção de possibilidades podem ser mais bem abordados, analiticamente, como a descrição de uma formação social cindida e conflituosa, constituída na tentativa de estabelecer um equilíbrio ou assentamento temporário no campo de forças, por meio de várias práticas e processos de luta e negociação. Talvez, movimentando-nos dessa maneira, seja possível não apenas reiterar que o conhecimento do mundo é condição da transformação social, mas superar a sensação de que ele hoje nos pareça impotente para cumprir tal tarefa.

Itania Maria Mota Gomes é professora titular da Universidade Federal da Bahia, docente permanente do Programa de PósGraduação em Comunicação e Cultura Contemporâneas e bolsista Produtividade em Pesquisa do CNPq. É doutora em Comunicação e Cultura Contemporâneas pela UFBA. Coordena o Centro de Pesquisa em Estudos Culturais e Transformações na Comunicação (http://tracc-ufba.com.br/).

itania@ufba.br

Elton Antunes é professor associado da Universidade Federal de Minas Gerais, pesquisador permanente do PPGCOM/ UFMG e bolsista de Produtividade em Pesquisa do CNPq. É doutor em Comunicação e Cultura Contemporâneas pela Universidade Federal da Bahia. Integra o Grupo de Pesquisa em Historicidades das Formas Comunicacionais 
(ex-press) e é pesquisador associado ao Núcleo de Estudos Tramas Comunicacionais: Narrativa e Experiência, ambos da UFMG.

eantunes@ufmg.br

\section{Referências}

ANTUNES, E. \& GOMES, I. Raymond Williams por ele mesmo: gestos epistemológicos e acenos políticos para (re)pensar a comunicação, VIII Historicidades dos Processos Comunicacionais, Salvador, UFBA, novembro de 2018.

FUCHS, C. Raymond Williams' communicative materialism. European Journal of Cultural Studies, v. 20 , n. 6, p. 744-762, 2017.

GOMES, I. Raymond Williams e a hipótese cultural da estrutura de sentimento. In: GOMES, Itania e JANOTTI JR., Jeder (Orgs). Comunicação e Estudos Culturais, Salvador, Edufba, 2011. Disponível em: http://www.repositorio.ufba.br/ri/handle/ri/5536

Articulações entre música e tecnocultura no Led Zeppelin. In: $24^{\circ}$ Encontro Nacional da Associação Nacional dos Programas de Pós-Graduação em Comunicação/ COMPÓS, 2015, Brasília. Anais do $24^{\circ}$ Encontro Nacional da COMPÓS. Brasília: COMPÓS, 2015. p. 1-15. Disponível em: http:// www.compos.org.br/biblioteca/compos-2015-8dfc2cf9-afd7-48a3-b942-4f8ded57cc74_2858.pdf

GOMES, I. \& ANTUNES, E. Raymond Williams por ele mesmo: gestos epistemológicos para pensar a comunicação, VIII Historicidades dos Processos Comunicacionais, Belo Horizonte, UFMG, maio de 2018.

GROSSBERG, L. Affect's Future: rediscovering the virtual in the actual In GREGG, M. \& SEIGWORTH, G. J. (Eds.). The Affect Theory Reader. Durham, USA: Duke University Press, 2010b, 402p.

Cultural Studies in the Future Tense, Durham/London: Duke University Press, 2010.

Dancing in Spite of Myself: Essays on Popular Culture. Durham/Londres: Duke University Press, 1997.

Lutando com anjos: os estudos culturais em tempos sombrios. MATRIZes, v. 9, p. 13-46, 2015.

. Under the cover of chaos: Trump and the Battle for the American Right. Londres: Pluto Press, 2018, 165p.

We gotta get out of this place: Popular conservatism and postmodern culture. London: Routledge, 1992.

HALL, S. “Estudos Culturais e seu legado teórico" (Trad. de Cláudia Álvares). In: SOVIK, Liv (Org.). Da Diáspora: identidades e mediações culturais, Belo Horizonte, Editora UFMG; Brasília, Representação da Unesco no Brasil, 2003, p. 199-218.

JONES, P. K. Williams, Raymond. In: The International Encyclopedia of Communication Theory and Philosophy. Hoboken, NJ, USA: John Wiley \& Sons, Inc., 2016. p. 1-5.

THOMAS, P. N. The contributions of Raymond Williams and E.P. Thompson to communication and social change theory and practice. European Journal of Communication. V. 32, n. 5, p. 405-418, 2017.

WILLIAMS, R. Literature and Sociology: in memory of Lucien Goldmann. New Left Review. 1/67, pg. 3-18, May/June, 1971.

WILLIAMS, R. Marxismo e Literatura. Rio de Janeiro: Zahar Editores,1979. 
Cultura. São Paulo: Paz e Terra, 1992.

Televisão: tecnologia e forma cultural. Boitempo Editorial, 2016.

Texto recebido em 28/02/2019

e aprovado em 25/04/2019. 